\section{Schmerzfrei ohne Opiumrausch}

Opium stillt Schmerzen, indem es Ionenkanäle in schmerzempfindlichen Zellen blockiert - daher empfehlen sich diese Kanäle als Ansatzpunkte einer Schmerzbehandlung, die ohne Opiumverabreichung auskommt. Das zeigt eine Forschungsgruppe aus der Marburger Universitätsmedizin gemeinsamen mit deutschen und amerikanischen Beteiligten in einer aktuellen Studie. Das Team um den Biologen Professor Dr. Johannes Oberwinkler klärte das Zusammenwirken von Molekülen auf, die an der Schmerzempfindung beteiligt sind. Die Ergebnisse sind soeben im Forschungsmagazin „e-Life“ erschienen (Dembla $S$ et al. Anti-nociceptive action of peripheral mu-opioid receptors by G-beta-gamma protein-mediated inhibition of TRPM3 channels, e-Life 2017, doi:10.7554/eLife.26280).

„Wie die zellulären Mechanismen funktionieren, durch die Opioidrezeptoren auf die Schmerzempfindlichkeit der Haut wirken, war bislang nicht bekannt“, erklärt Professor Dr. Johannes Oberwinkler vom Institut für Physiologie und $\mathrm{Pa}$ - thophysiologie der Philipps-Universität, der die Untersuchungen leitete.

Um herauszufinden, welchen Einfluss die sog. TRPM3-Kanäle auf das Schmerzempfinden ausüben, führten Oberwinkler und sein Team Experimente an Zellkulturen durch: Sie aktivierten Opioidrezeptoren, indem sie Morphin zusetzten dieser Opiumbestandteil ist seit langem als Kopplungspartner der Rezeptoren bekannt. Außerdem testete die Forschungsgruppe die Wirkung der morphinähnlichen, synthetischen Substanz DAMGO.

Das Ergebnis: Schaltet man Opioidrezeptoren an, indem man sie durch Morphin oder DAMGO reizt, so hemmen sie die Aktivität der TRPM3-Kanäle. Diese sind dann zum Beispiel weniger durchlässig für Kalzium- und Natrium-Ionen als normalerweise. Wie die Forschungsgruppe weiter ermittelte, lassen sich auf diese Weise Schmerzempfindungen tatsächlich lindern.

Das Team identifizierte darüber hinaus weitere Moleküle, die an der Wechselwirkung zwischen Opioidrezeptoren und TRPM3-Kanälen beteiligt sind. Diese Moleküle vermögen die Kanalproteine ebenfalls zu hemmen.

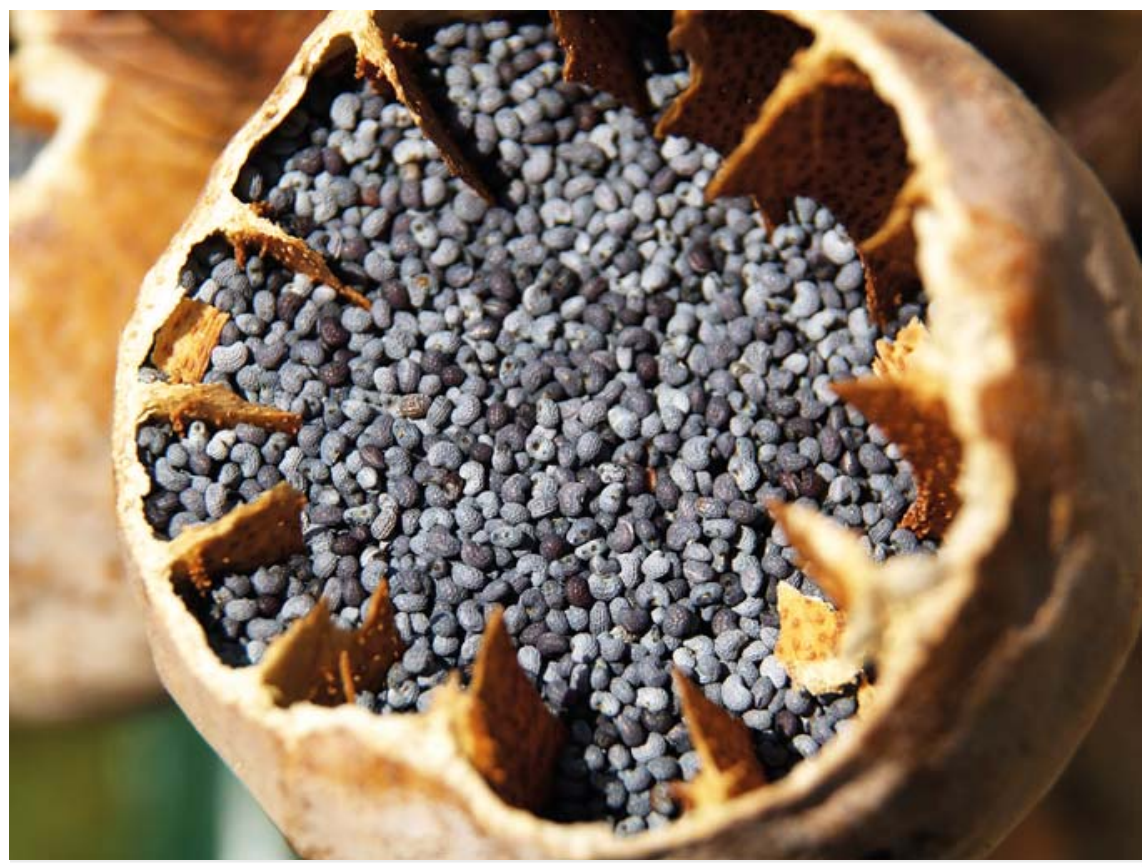

Abb. 1 Gibt es bald Alternativen zu Opium? Quelle: merian/istockphoto

Die Schlussfolgerung: Wenn es gelingt, die TRPM3-Kanäle auf andere Weise als durch Opiumbestandteile zu blockieren, erzielt man ebenfalls schmerzstillende Ergebnisse, aber unter Umständen mit weniger nachteiligen Folgen als bei einer Opiumverabreichung. „Bei Mäusen zeigen sich keine unerwünschten Nebenwirkungen, wenn ihnen das TRPM3-Gen fehlt", führt das Autorenteam um Oberwinkler hierzu aus. „Medikamente, die sich gegen TRPM3-Kanäle richten, könnten daher ein brauchbares Mittel gegen Schmerz sein.“

Nach Angaben der Philipps-Universität Marburg 